\section{$\underset{\substack{\text { hommes } \\ \text { \& migrations }}}{ }$}

\section{Hommes \& migrations}

Revue française de référence sur les dynamiques

migratoires

$1311 \mid 2015$

Femmes et migrations

\title{
Philippe Dewitte, rédacteur en chef
}

L'artisan d'une revue incontournable dans le champ migratoire

\section{Catherine Wihtol de Wenden}

\section{OpenEdition \\ 1 Journals}

\section{Édition électronique}

URL : http://journals.openedition.org/hommesmigrations/3327

DOI : 10.4000/hommesmigrations.3327

ISSN : 2262-3353

\section{Éditeur}

Musée national de l'histoire de l'immigration

\section{Édition imprimée}

Date de publication : 1 juillet 2015

Pagination : 134-135

ISBN : 978-2-919040-32-2

ISSN : $1142-852 X$

Référence électronique

Catherine Wihtol de Wenden, « Philippe Dewitte, rédacteur en chef », Hommes \& migrations [En ligne], 1311 | 2015, mis en ligne le 09 février 2016, consulté le 14 septembre 2020. URL : http:// journals.openedition.org/hommesmigrations/3327 


\title{
SPÉCIAL 50 ANS
}

\section{PHILIPPE DEWITTE, RÉDACTEUR EN CHEF L'ARTISAN D'UNE REVUE INCONTOURNABLE DANS LE CHAMP MIGRATOIRE}

\author{
Par CATHERINE WIHTOL DE WENDEN, directrice de recherche \\ au CNRS (CERI).
}

$D_{\&}$ hilippe Dewitte est entré à la revue Hommes \& Migrations à la fin des années 1980, un peu après que Jacques Hauser m'ait demandé de faire partie du comité de rédaction. Sa posture discrète, quoique efficace, et respectueuse du père Ghys, lui a permis de s'imposer par son professionnalisme, son goût du travail bien fait, sa position de journaliste sans concession à l'égard du pouvoir en place, quel qu'il fût, ses idées bien tranchées et ses intuitions sur les dossiers, les auteurs, la qualité des articles, des illustrations. Il aimait souvent à rappeler, quand un thème avait été soulevé par le comité de rédaction comme sujet à traiter : "Oui, mais a-t-on un auteur?"

Il a traversé sans encombre mais non sans soucis les péripéties de la revue : le décès brutal du père Ghys, qui dirigeait l'association Amana sans partage, les fins de mois difficiles du temps de l'association des Amis d'Hommes \& Migrations, puis l'entrée de la revue à l'Agence pour le développement des relations interculturelles (Adri) et, enfin, son incorporation dans la Cité nationale de l'histoire de l'immigration.

\section{Le renouvellement de la revue}

En une quinzaine d'années, Philippe Dewitte a réussi à faire d'une revue marquée par son passé caritatif et militant une référence incontournable des travaux sur les migrations, traitant des thèmes les plus en pointe, en y conviant les meilleurs auteurs, avec toujours le souci de conserver un style et une approche accessibles à un public plus large que celui de l'université ou des administrations spécialisées. Son apport en matière éditoriale a été, tout d'abord, l'ajout de longs entretiens, souvent menés par lui-même auprès de décideurs, d'auteurs et de militants. Puis, le changement de la maquette, de la couverture, l'introduction de nouvelles rubriques comme la cuisine et le cinéma, de dessins et caricatures, de photos, l'allongement de la taille des textes, la faculté de refuser certains textes et certains auteurs pour manque de professionnalisme. Perfectionniste, il a modifié plusieurs fois la couverture tout en gardant les trois couleurs rouge, blanc noir, dans des formats divers.

Dans son carnet d'adresses, se côtoyaient des intellectuels consacrés, des intellectuels de terrain, des militants associatifs, des chercheurs, des hauts fonctionnaires, des essayistes, il impressionnait par son éclectisme et sa diversité. Ce carnet contrastait avec sa simplicité, sa solitude parfois face aux enjeux de la revue, ses coups de gueule à l'égard d'auteurs de textes qualifiés de "faiblards" ou qui ne remplissaient pas leurs engagements, et son peu de goût pour les hiérarchies.

Les réunions du comité de rédaction étaient toujours un moment de convivialité et d'échanges : d'abord dans le décor de patronage passablement décalé de la rue de la Duée, puis dans ce 
1999, et, enfin, d'un livre en format de poche, Deux siècles d'immigration en France, paru à La Documentation française en 2003.

Philippe militant, animant des ateliers lors d'universités d'automne ou de colloques à la Ligue des droits de l'homme. II n'hésitait pas à brandir sa démission de journaliste en cas d'intrusion du pouvoir de tutelle. Je me souviens de l'épisode d'un numéro sur les frontières du droit d'asile, que j'avais coordonné. II s'était retrouvé avec Luc Gruson face au directeur de la DPM (direction de la population et des migrations)...

Philippe animateur de débats : à la Maroquinerie, un café littéraire pour présenter des numéros de la revue et leurs auteurs; à la Sorbonne, pour promouvoir, sous forme de conférence-débat, son ouvrage de La Découverte ; ou plus urbain, malgré ses réticences envers les mondanités, célébrant l'anniversaire d'Hommes \& Migrations dans les locaux de Génériques et participant à un concert de musique classique organisé par l'Amana et une fondation privée. Philippe enseignant sur les questions liées à l'immigration, restaurant style salle des fêtes de province très Troisième République de la rue du FaubourgSaint-Antoine et, enfin, dans le décor berbère soigné de La Colline oubliée, rue Jean-Macé, où Philippe Dewitte se plaisait à rappeler ce clin d'œil à la laïcité, tout en ajoutant qu'il avait participé au conseil éditorial, plusieurs années durant, de la revue jésuite Projet.

\section{Un intellectuel engagé}

Mais il y avait aussi Philippe Dewitte auteur, d'abord d'une thèse d'histoire à l'université de Vincennes sur les troupes coloniales africaines, puis d'articles dans Hommes \& Migrations et d'un ouvrage devenu un classique, Immigration et intégration, l'état des savoirs, paru à La Découverte en dans les universités américaines à Paris réunies à Reid Hall (centre universitaire pour les étudiants américains), rue de Chevreuse. Philippe en voyage, très enthousiaste lors de sa venue à l'université de Thallahassee avec Renate, au nord de la Floride, chez notre collègue et ami Alec Hargreaves. Philippe concepteur des thématiques de la future exposition permanente du Musée national de l'immigration, où il s'est engagé corps et âme malgré l'extrême faiblesse de ses derniers mois de vie. Mais l'essentiel pour lui, c'était la revue : on avait l'impression que Philippe Dewitte et la revue ne faisaient qu'un, qu'il était totalement investi dans sa tâche, que seule la maladie et la mort ont pu les séparer.

/// Article initialement paru dans Hommes \& Migrations, $n^{\circ} 1257$, septembre-octobre 2005 . 